Artigos 



\title{
O Processo de Morte na História de José o Carpinteiro*
}

Eduardo Gross ${ }^{1}$

\section{RESUMO}

O presente texto analisa o apócrifo História de José o Carpinteiro a partir da descrição do processo de morte que este apresenta, traçando para isto paralelos com as fases por que passam pacientes terminais conforme retratadas por Elisabeth Kübler-Ross.

\section{PALAVRAS-CHAVE}

Morte, José o carpinteiro, Kübler-Ross

\begin{abstract}
The present text analyses the apocriphal History of Joseph the Carpenter from the viewpoint of the description of the death process presented by it; in order to do that, it traces parallels with the phases through which terminal patients pass, as they are described by Elisabeth Kübler-Ross.
\end{abstract}

\section{KEYWORDS}

Death, Joseph the carpenter, Kübler-Ross

\footnotetext{
* Originalmente publicado em: RTL. Revista Teológica Londrinense, Londrina, v. 4, p. 39-56, 2002.

1 Doutor em teologia pela EST (São Leopoldo - RS), professor no PPCIR (Programa de Pós-Graduação em Ciência da Religião) da Universidade Federal de Juiz de Fora - MG.
} 


\section{Introdução}

A morte não é bem-vinda, sob condições normais. Lidar com ela, no entanto, é uma necessidade intrínseca à vida. E é bom que isso se dê de forma explícita, sem a negação da realidade da morte. As religiões, em particular, precisam apresentar suas reflexões sobre ela. Isso ocorre por meio de representações míticas, poéticas ou narrativas, por exemplo. Contrasta com isso a realidade mascaradora em que vive a cultura moderna.

É a morte que se esconde e que é vergonhosa, o grande fracasso da humanidade. Há uma supressão da manifestação do luto, a sociedade condena a expressão e a vivência da dor, atribuindo-lhes uma qualidade de fraqueza. Há uma exigência de domínio e controle. A sociedade capitalista, centrada na produção, não suporta ver os sinais da morte. Os rituais do nosso tempo clamam pelo ocultamento e disfarce da morte, como se esta não existisse. ${ }^{2}$

Às vezes, sem se dar conta, também no cristianismo esse triunfalismo moderno-capitalista penetra. A confissão de fé na ressurreição acaba sendo lida de forma unilateral, como se a dor, o sofrimento, a perda e o luto não fossem parte da existência real. Em termos simbólicos, pode-se dizer que nesses casos o domingo de páscoa é absolutizado, em detrimento da lembrança da sexta-feira de paixão. Diante disto, é necessário acentuar a importância do equilíbrio entre o reconhecimento da realidade e a confissão da esperança.

A História de José o Carpinteiro é um texto cristão apócrifo. Conforme o editor da tradução espanhola, é possível que o texto tenha sua origem no Egito dos séculos IV ou V e que a língua original tenha sido o grego. A tradução espanhola se baseia nas versões sahídica e boahírica, já que a versão original não foi redescoberta. ${ }^{3}$

É bastante patente que se trata de uma composição baseada em elementos traditivos diversos. Isso se vê em primeiro lugar pela distinção de formas utilizadas: salmos, narrativas, discursos teológicos. Em segundo

2 KOVÁCS, Maria Júlia. Morte e Desenvolvimento Humano, p. 151.

3 SANTOS OTERO, Aurélio de (ed.) Los Evangelios Apócrifos, p. 333-344. 
lugar, o fato de que a versão sahídica contém somente ${ }^{4}$ os capítulos 13 a 21 também é um indício de que a composição final possa ter agregado elementos diversos. ${ }^{5}$ Em terceiro lugar, a apresentação de um resumo da vida de José no capítulo 14 mostra que não haveria problema algum na circulação de uma versão que deixasse de apresentar os elementos relativos à infância de Jesus. Assim, a impressão que o texto causa é de que, a um relato sobre a morte de José, foram acrescentados elementos relativos à infância de Jesus com intuito de justificação teológica. Para efeitos da presente análise, entretanto, é justamente a parte central do texto que interessa, pois ali se encontra a narrativa do processo de morte de José. O editor observa que a versão que utiliza como base é a boahírica (a mais extensa), apontando em notas para variantes textuais da sahídica e da árabe. ${ }^{6}$

\section{Síntese do texto}

A introdução do texto parece um grande cabeçalho que visa dar autenticidade à narrativa, apresentando-a como a transcrição feita pelos discípulos de um relato do próprio Jesus no Monte das Oliveiras. Ela parece querer fundamentar a reverência ao dia da morte de José. O primeiro capítulo tem um caráter introdutório à narrativa e traz um discurso de Jesus, que sintetiza as tarefas evangelizadoras dos discípulos e aponta com ênfase para a necessidade de preparação para o julgamento divino. O texto pressupõe tal juízo ocorrendo após a morte (1.6).

Os capítulos 2 a 9 apresentam esquematicamente a vida de José desde o período prévio ao seu casamento com Maria até a volta do Egito à Galiléia. Em conformidade com vários outros apócrifos cristãos e também com a tradição tardia na antiguidade, também a História de José o Carpinteiro visa nesse trecho solucionar alguns embaraços causados pelos textos dos evangelhos canônicos à teologia "oficial" que está se constituindo: a) José é descrito como viúvo de um primeiro casamento, de modo que os irmãos e as irmãs de Jesus citados nos evangelhos canônicos

\footnotetext{
${ }^{4}$ Ibid., p. 333.

5 SANTOS OTERO, Aurélio de (ed.). Los Evangelios Apócrifos, p. 333.

${ }^{6}$ Ibid., p. 335, nota.
} 
ficam representados como filhos somente dele; b) José, portanto, é retratado como um idoso ${ }^{7}$, enquanto que Maria é descrita como uma menina de 12 anos quando o casamento é contratado, o que justificaria a possibilidade de sua virgindade perpétua; c) Maria, desde os 3 até os 12 anos, é apresentada como vivendo no templo, de certo com a dupla intenção de assegurar sua virgindade e de apresentá-la como especialmente dedicada a Deus desde a mais tenra idade; d) o casamento de ambos é decidido por um sorteio feito entre todas as tribos de Israel, de modo que a providência divina seja vista como artífice da união. Além disso, apresenta-se uma versão harmonizante entre Mateus e Lucas dos episódios da concepção de Maria, dos sonhos de José (quanto à concepção e quanto à ameaça de Herodes), do recenseamento, da ida a Belém, da fuga ao Egito e da volta à Galiléia.

Nos capítulos 10 a 12 há uma transição da época das histórias relativas à infância de Jesus para a proximidade da morte de José. Este é descrito como tendo 111 anos, em perfeito juízo e em boa condição de saúde (cap. 10). Apesar disso, ele adoece e um anjo vem anunciar-lhe a morte, o que é ocasião para a ida de José ao templo de Jerusalém (cap. 12). Jesus é descrito como filho respeitoso, que, conforme o costume, chamava José de pai e Maria de mãe (cap. 11).

A transição se completa com o capítulo 13, que traz uma oração de preparação para a morte, descrita como a saída da alma do corpo (cap. 13.2 e 4). Inserida na narrativa, ela aparece como uma oração feita por José no templo de Jerusalém. Do ponto de vista formal, poderia ser uma oração tradicional de preparação para a morte. Do capítulo 14 ao 21 ocorre a descrição pormenorizada do processo de morte, que será analisada logo a seguir. O capítulo 22 apresenta uma oração de intercessão de Jesus, e serve de transição para a descrição dos fatos posteriores à morte. A cosmovisão mítica deste capítulo transparece nas intercessões: Jesus solicita que a alma de José passe sã e salva até pelo sétimo éon, sem ser importunada pelos espíritos malignos que habitam este trajeto.

Estes acontecimentos posteriores à morte iniciam, pois, o relato mítico do processo de saída da alma. No capítulo 23, Jesus coloca a alma de José

\footnotetext{
7 No resumo do capítulo 14, se diz que José contraiu o primeiro matrimônio aos 40 anos, esteve casado por 49 anos e ficou viúvo durante 1 ano antes de casar com Maria.
} 
nas mãos dos arcanjos Miguel e Gabriel, que a levam aos braços de Deus Pai. Aqui a versão sahídica é oferecida em nota pelo editor, já que apresenta um drama bem mais longo e vivo da luta da alma com os poderes que a querem subjugar em sua ida ao céu. A morte aparece personificada como uma entidade que precisa pedir licença a Jesus para entrar na casa (versão sahídica, 23.6-7) - ela não é, pois, um poder maligno como os gênios que o texto apresenta espreitando no trajeto até o céu (versão sahídica, 23.13) -, mas é um poder submisso a Deus, uma cumpridora de deveres (cf. tb. o texto da versão boahírica no capítulo 28, de caráter teológico). Em ambas as versões anjos cantam louvores durante o trajeto da alma até o céu.

Os capítulos 24 a 27 apresentam os acontecimentos relacionados ao processo de luto: o luto na família (cap. 24), o luto em Nazaré (cap. 25), promessas de Jesus relativas à reverência da memória de José (cap. 26), o sepultamento (cap. 27 e 29). Os capítulos 28, 30, 31 e o epílogo apresentam um diálogo teológico entre Jesus e os discípulos sobre a relação entre a morte e a queda de Adão, a subida ao céu de Elias e de Enoque e um novo convite à reverência da memória de José.

Como se percebe, o núcleo central do texto como um todo está na apresentação do processo da morte. Isso é ainda mais patente na parte comum às duas versões principais, mas transparece também na parte final, própria à versão boahírica. Não se trata, entretanto, de um texto mórbido nem fascinado pela morte. Ele lida com ela e reflete sobre ela a partir da sua interpretação particular da esperança cristã. Leituras desta narrativa de um ponto de vista dogmático certamente poderiam suscitar debates quanto à filiação teológica de seu autor e problematizar a cosmologia que lhe serve de pano de fundo. Mas esta não é a intenção aqui. A presente análise visa meramente apontar para a atenção que a narrativa dedica a esse elemento humano intrínseco à vida que é a morte.

\section{A descrição do processo de morte de José}

\section{a) A oração de preparação para a morte (capítulo 13)}

Diante da morte, José se sente ameaçado. A sensação de ameaça é ocasião para solicitar o auxílio do arcanjo Miguel (v. 2). Neste ponto, 
o principal pedido é que este o auxilie no sentido de que o processo de morte o poupe da dor e do tormento (v. 2-5). Nota-se que neste ponto o temor não transparece como sendo em relação à morte em si, mas ao seu processo. Ao mesmo tempo em que no texto aparece este pedido, se faz também a observação de que dor e tormento são um fator universalmente presente nos seres vivos:

Porque a morte é para todos causa de dor e tormento, quer se trate de um homem, de um animal doméstico ou selvagem, ou ainda de um verme ou pássaro; - em uma palavra, é muito doloroso para toda criatura que vive sob o céu e em que alenta um sopro do espírito ter de enfrentar a agonia de ver sua alma separada do seu corpo (v. 3-4). ${ }^{8}$

Trata-se, aqui, de uma singela confissão do caráter criatural do ser humano. A morte é, neste sentido, mensageira da participação do ser humano no processo cósmico da vida. Ao mesmo tempo, fica patente o paradoxo com que o ser humano se defronta ao encarar a morte. Apesar de ser o final da vida, ela representa um elemento comum a todos os seres vivos. Desta forma, mais interessante do que especular sobre a concepção de alma que se espelha nestes versículos é atentar para esta comunhão na criaturalidade que a morte testemunha.

O fundo mítico pressuposto pela oração se revela nos pedidos concretos de José: há pedidos especiais de proteção com relação à presença do anjo da guarda (v. 6), à ameaça dos espíritos malignos que se encontram no trajeto da alma até o céu (v. 7), à necessidade de superar a barreira representada pelo cão Cérbero (v. 8), ao auxílio necessário para comparecer ante o tribunal do juízo (v. 8), à ajuda para transpor o rio de fogo que separa a alma da visão da face de Deus (v. 9). Quanto à cosmovisão pressuposta, é notória a sua riqueza em imagens, herdadas de tradições diversas - gnósticas, helênicas, apocalípticas. Elas representam as ameaças do desconhecido, que ganham figuras concretas. $\mathrm{O}$ texto não parece tão interessado em privilegiar alguma dessas tradições de representação do desconhecido, mas em conseguir se comunicar com o universo dos seus leitores. Sem pretender construir uma síntese dessas

${ }^{8}$ SANTOS OTERO, Aurélio de (ed.) Los Evangelios Apócrifos, p. 340. 
imagens tão diversas, o diálogo com o universo conceptual do fiel parece ser o objetivo principal. Assim, o pedido pelo auxílio do arcanjo Miguel mostra que o centro do temor está em enfrentar essas ameaças desconhecidas de forma solitária.

Por fim, a oração conclui com um louvor à misericórdia divina que é solicitada como consolo diante da morte assim como o é diante da vida (v. 10). A confissão de fé na bondade divina durante a existência terrena fortalece a confiança na ação dessa misericórdia também diante do desconhecido que está pela frente.

\section{b) A doença de José (capítulos 14-15)}

Depois da oração que apresenta os coloridos simbólicos acima descritos, a situação concreta de José é relatada de um modo bastante realista. Isso mostra como o texto alterna a redação mítico-simbólica, que expressa significado, com a descrição baseada nas experiências factuais da vida, o que por seu turno permite a identificação dos leitores com o texto.

A doença que acomete José é descrita como a mais forte da sua vida (14.1-2). Ainda que toda doença seja um prenúncio da finitude humana, a doença mortal é particularmente reconhecida como tal. Mesmo que no texto isso seja antecedido por um anúncio divino, trata-se de uma proposta de superação da negação no caso de doença terminal.

O confronto com a doença terminal dá ocasião para a apresentação de um resumo da vida de José (14.3-6). De um ponto de vista formal, trata-se de uma indicação do caráter composto do texto, já que tal resumo não seria necessário à medida que o início do escrito apresentava uma "história de José". Por outro lado, a construção textual como se encontra hoje aponta para a recapitulação da vida a que o confronto com a morte dá ensejo.

O auge do realismo se dá na descrição do estado de José enfermo: palidez, perda de lucidez, falta de apetite, perda da coordenação motora (15.3-4). Estes elementos concretos impedem a idealização da morte. Ela é descrita como processo doloroso. E se a morte de um personagem simbólico no universo religioso é descrita assim, tanto mais o leitor encontra ali uma compreensão da situação real com que ele deve enfrentá-la. Este drama aparece de modo mais pungente quando inicia o dia da morte. 
Agitação no leito, gemido e lamento em forma de gritos indicam que o drama chega ao seu ponto alto (15.5).

\section{c) O salmo de lamentação (capítulo 16)}

Trata-se de uma lamentação composta no estilo do livro de Jó, mas com um tom um tanto quanto moralista - talvez mais próximo à visão dos amigos de Jó. Em si é uma lamentação de caráter bastante geral. A impressão de um lamento que pode ter servido como oração tradicional diante da morte é dada ao se ler os últimos versículos na versão boahírica, que podem, no entanto, ser também uma moldura composta pelo redator:

Esta é a angústia que se apoderou de meu pai Jacó em sua agonia, a qual veio hoje me alcançar a mim, infeliz. - Mas tu, Jesus, Deus, que és meu advogado, cumpre em mim tua divina vontade (16.14-15). ${ }^{9}$

Como se vê, há uma ambiguidade entre Jacó pai de José e Jacó pai de todo o Israel. Além disso, o lamento pronunciado por José na presença de Jesus na narrativa pode ser relido como um lamento do fiel, tendo Jesus presente por ocasião da sua oração.

\section{d) O consolo de Jesus (capítulo 17)}

O texto relata que quando Jesus entra no quarto, José inicia uma série de exclamações cujo alvo é a confissão da divindade de Cristo. Isto se dá primeiro de um modo direto, na forma de confissão propriamente dita. Em seguida, aparece de forma mítica na reafirmação do milagre da concepção virginal. Por fim, é reafirmado de modo simbólico com a narrativa de um milagre de cura por parte de Jesus menino.

O texto todo parece aqui dar espaço para as lembranças de vida de José. A entrada de Jesus no quarto é um consolo para suas lamentações à medida que serve de ponto de encontro com as experiências de vida de José. Nesse sentido, Jesus tem aqui uma dupla função: por um lado ele é para José o salvador que ele confessa vai salvar sua alma; por outro

9 Ibid., p. 342-343. 
lado Jesus é o vínculo com a existência terrena que ele está deixando. As "duas naturezas" de Cristo agem afetivamente no processo de morte de José.

\section{e) A aflição de Maria (capítulo 18)}

O capítulo é ocasião para apresentar o caráter universal da morte. Nele Jesus começa a refletir sobre a morte na cruz que irá sofrer. Em seu diálogo com Maria, aponta para o fato de que também ela deverá experimentar a morte. Por fim, o caráter generalizante engloba também o leitor. A presença diante do leito de José é ocasião para que a realidade da morte se torne consciente para cada pessoa que ali se encontra, o leitor inclusive.

O que se percebe aqui é a empatia que a morte produz. A dor provocada pela proximidade com a morte não é só a dor pela perda de um ente querido. Ela também significa a perda da onipotência pessoal diante da existência. A morte alheia adverte quanto à própria finitude.

\section{f) As dores de José (capítulo 19)}

O capítulo 19 é outro auge da descrição realista. A morte já se apodera de José por alguns momentos, simbolizados por sua incapacidade de falar. O olhar é uma forma de comunicação que lhe resta, de modo que José crava sua vista em Jesus (v. 3). Se isso pode ser lido como apontando para a esperança de José na salvação simbolizada por Jesus, também pode ser lido como a indicação de que para todo moribundo o contato com as pessoas que o acompanham é um relacionamento importante para enfrentar a sua solidão diante da morte. $O$ fato de que José dirige o olhar para o céu e geme (v. 4) é outra indicação de que o olhar é uma forma de comunicação que lhe resta, desta vez com o próprio âmbito do divino.

Outra forma de comunicação importante é o tato. Jesus segura as mãos de José e este solicita que Jesus não o abandone aos inimigos (v. 5). Jesus aparece como pessoa que não se intimida com a proximidade da morte. O temor provocado internamente na pessoa que está próxima do moribundo pode prejudicar o auxílio que a presença acolhedora tem condições de prestar. Compare-se isso com o relato da psicóloga Rachel Léa Rosenberg: 
A gente não se aproxima fisicamente do velho, você abraça e beija gente jovem, pega na mão. No velho você encosta no máximo, se for da família você dá beijinhos. Então a pessoa mais velha tem uma história atual de muito pouco contato com outro. ${ }^{10}$

Se já há resistência quanto ao contato físico com pessoas idosas, quanto mais quando se encontram moribundas! Nesse sentido, o texto tem um caráter desafiador. A importância do tato aparece também na sequência, quando Jesus toca o peito de José e nota que sua alma já subiu à sua garganta (v. 6). Aqui se reflete a concepção que identifica a respiração com a alma, esta é o sopro da vida. Quando este cessa, a alma deixou sua morada corporal. Diante dessa iminência da morte, o texto retrata a presença das lágrimas, do tormento e do decaimento de José.

\section{g) A agonia (capítulo 20)}

Enquanto o capítulo anterior narrava realisticamente a proximidade da morte no que se refere à pessoa moribunda, o capítulo 20 o faz quanto aos seus efeitos sobre as pessoas próximas. Maria põe as mãos nos pés de José e se engana. Ela pensa que a febre o está deixando, quando na verdade ele está morrendo (v. 1-3). Trata-se de um retrato da negação da morte, uma tentativa de se refugiar numa ilusão diante do inevitável.

Jesus aparece como o personagem que não se deixa iludir. Ele chama os filhos para terem um último diálogo com o pai (v. 4-5). Aqui a aceitação da morte por parte dos parentes próximos começa a ocorrer. Os diálogos no leito de morte são recorrentes no Antigo Testamento, por exemplo. São ocasião em que os patriarcas concedem bênção e expressam esperanças com relação ao futuro de sua progênie. Lísia, uma das filhas, identifica a doença como a mesma que vitimou sua mãe (v. 6-7). Trata-se de uma identificação com um evento passado. A morte aparece como velha conhecida. A experiência passada auxilia na elaboração emocional necessária no presente.

${ }^{10}$ ROSENBERG, Rachel Léa. Envelhecimento e morte. In: KOVÁCS, Maria Júlia. Morte e desenvolvimento humano, p. 86. 
O capítulo termina com pranto generalizado - incluindo os filhos, Maria, José e o próprio Jesus (v. 8). A tristeza da separação não é maquiada a partir da dogmática religiosa. O luto é apresentado como uma característica da existência humana finita. A esperança só pode ser real se aceitar as contingências dessa existência, do contrário se trata de uma negação, de uma ilusão. A participação de todos estes personagens simbólicos no pranto é uma indicação do caráter do texto: Uma narrativa realista, no sentido de retratar fatos da existência sem idealização desmedida, e simultaneamente uma narrativa pedagógica, já que esses personagens fornecem modelos para lidar com os mesmos fatos na vida.

\section{h) A morte (capítulo 21)}

Contrastando com o caráter realista dos capítulos precedentes, a narrativa da morte propriamente dita é feita de uma forma simbólica. O relato mítico inicia com a morte vindo do sul, acompanhada de seus assistentes. Junto vem também o diabo com seus assistentes em fogo (v. 1). A imagem é a de um cortejo de horror. As figuras simbólicas expressam o terror do moribundo. Um certo tom moralista não deixa de estar presente no momento em que o texto lembra que ainda maior é o terror sentido pela pessoa pecadora (v. 2). Diante da visão deste cortejo terrível, José rompe em lágrimas (v. 3). É curioso que a narrativa diga que só José e Jesus podem perceber a presença dessas figuras (v. 7) - José como vítima, Jesus de certo como o personagem que participa simultaneamente de duas dimensões do cosmo. Talvez a situação de liminaridade de José também explique por que ele pode perceber a presença destas figuras míticas. Enquanto moribundo, José já faz parte, parcialmente, desta outra dimensão.

Quando José expira, sua alma procura um refúgio onde se abrigar (v. 4). Ocorre uma disputa pela sua posse, disputa na qual Jesus enfrenta o diabo e seu cortejo que acabam fugindo (v. 5-6). Após a expulsão dos poderes infernais, a morte se sente apavorada na presença de Jesus (v. 8). Nota-se que é fundamental distinguir os dois grupos míticos que participam do cortejo. $\mathrm{O}$ da morte é um cortejo de serviçais, que não faz parte do cortejo do diabo. Este sim é maligno, e é afastado por Jesus por causa do seu objetivo de escravizar a alma. $\mathrm{O}$ da morte não é idealizado 
como se fosse belo - também a morte pode servir ao diabo. Mas não necessariamente é assim. A morte tem de cumprir seu papel. Amedrontada porque Jesus pôs o diabo em fuga, ela não ousa agir. Percebendo que é empecilho para que a morte entre no recinto e cumpra seu papel, Jesus dá licença para a ação da morte.

O significado deste relato mítico é poderoso. Sem idealização, a morte é vista como inevitável e, importante, como parte da existência. Ela é retratada como semelhante ao mal, mas não como igual a ele nem simplesmente como sua serva. Ela age de forma submissa aos poderes maiores do bem e do mal. Por outro lado, Jesus, enquanto representante da esfera do divino, não impede simplesmente a ação da morte. Não se ratifica aqui uma religiosidade idealizada, negadora da realidade. Submissa ao poder divino, também a morte é instrumento nas mãos de Deus.

\section{As fases da morte no doente terminal}

Dentre outras possibilidades, no presente estudo se optou por traçar um paralelo entre o texto acima analisado e as fases do processo de morte do doente terminal assim como descritas por Elisabeth Kübler-Ross. Esta é uma conhecida psiquiatra, que desenvolveu seus escritos a partir do trabalho de acompanhamento de doentes terminais em hospitais, além de ter iniciado todo um movimento, presente hoje em muitos países, com o intuito de proporcionar um acompanhamento digno do processo de morte. Trata-se de uma iniciativa valorosa, à medida que se contrapõe à tendência despersonalizante da tecnologia hospitalar.

Em Sobre a morte e o morrer, um escrito simples mas tocante, Kübler-Ross propõe cinco estágios no processo de lida com a realidade da morte. Estes estágios se referem em primeiro lugar ao processo por que passa a pessoa moribunda, mas são percebidos paralelamente também nas pessoas que convivem mais proximamente e têm relações emocionais com ela. ${ }^{11} \mathrm{O}$ esquema básico é:

${ }^{11}$ Cf. KÜBLER-ROSS, Elisabeth. Sobre a morte e o morrer, p. 174. 

a) Primeiro estágio: Negação e isolamento
b) Segundo estágio: A raiva
c) Terceiro estágio: Barganha
d) Quarto estágio: Depressão
e) Quinto estágio: Aceitação
f) Esperança

O estágio da negação é descrito como um primeiro momento no qual a pessoa enfrenta a notícia de sua morte iminente com a fuga. Isso porque a notícia é tão chocante, que não pode ser simplesmente aceita.

A negação funciona como um pára-choque depois de notícias inesperadas e chocantes, deixando que o paciente se recupere com o tempo, mobilizando outras medidas menos radicais. ${ }^{12}$

Em princípio, esta negação é temporária, à medida que o tempo decorre certas medidas são tomadas pela própria pessoa no sentido de preparar sua despedida. Por outro lado, ela também registra que por vezes a negação continua em função não das condições emocionais da pessoa, mas porque ela visa poupar o sofrimento de familiares ou mesmo da equipe hospitalar preocupada com o tratamento. ${ }^{13}$ Se a negação persistir, no entanto, durante todo o processo, alguns procedimentos concretos podem ser prejudicados, principalmente uma despedida consciente dos entes queridos e a possível resolução de pendências no relacionamento com eles. Em todo caso, tal negação não deveria ser confundida com uma esperança autêntica, nem com uma fé religiosa.

O segundo estágio é o da revolta diante da situação inevitável já reconhecida como tal. Trata-se da raiva pela consciência da perda do controle sobre a própria vida. Kübler-Ross adverte que este é um estágio muito difícil para quem está próximo da pessoa moribunda. ${ }^{14}$ Isso porque a expressão dessa revolta se dá em relação às pessoas de seu relacionamento. Ela pode se dar, por exemplo, na forma de raiva contra parentes

\footnotetext{
12 Ibid., p. 50.

13 Ibid., p. 53.

${ }^{14}$ Ibid., p. 62.
} 
que são culpabilizados pela situação, contra médicos ou enfermeiros que não estariam cumprindo bem seus deveres ou mesmo contra Deus. Note-se que para quem lida com a pessoa moribunda pode haver uma tendência a desejar o retorno à situação anterior de negação, mais tranquila apesar de menos real. Especialmente pessoas religiosas podem confundir a passagem do primeiro ao segundo estágio como passagem da fé à descrença. Diante disso, a lembrança de textos bíblicos como as lamentações de Jó e dos Salmos servem de alerta. As lamentações presentes no texto da História de José o carpinteiro lhes são paralelas, neste sentido.

O terceiro estágio é descrito como barganha. O reconhecimento de que com a morte se está diante de um poder que não pode ser dominado faz com que se tente estabelecer negociações. Estas podem se referir ao comportamento no ambiente em que a pessoa se encontra, à amabilidade com que ela trata os membros de sua convivência, à realização de preceitos de natureza religiosa. Tais negociações podem também se manifestar na forma de pedidos para participar de certos eventos artísticos ou cerimônias familiares. Trata-se de um paralelo notável com as promessas infantis de bom comportamento tendo em vista a obtenção de um favor. Mesmo quando não enunciado claramente, no caso de pessoas moribundas o favor esperado é o prolongamento da vida.

A depressão aparece como o quarto estágio no esquema de Kübler -Ross. Trata-se do momento em que se aprofunda o sentimento de perda. Ela distingue esta depressão, que descreve como preparação profunda para a despedida, da depressão mais leve que ocorre nos primeiros momentos de comunicação do estado terminal. Se antes a pessoa precisava ser animada, agora ela precisa ser compreendida.

O paciente não deveria ser encorajado a olhar o lado risonho das coisas, pois isto significaria que ele não deveria contemplar sua morte iminente. (...---) O paciente está prestes a perder tudo e todos a quem ama. Se deixarmos que exteriorize seu pesar, aceitará mais facilmente a situação e ficará agradecido aos que puderem estar com ele neste estado de depressão sem repetir constantemente que não fique triste. ${ }^{15}$

${ }^{15}$ Ibid., p. 97. 
Significativa é a atitude das demais pessoas diante dessa situação. Kübler-Ross entende que se trata de uma depressão preparatória, importante para que a pessoa internamente vivencie e elabore os sentimentos relacionados com sua experiência. Assim, a pessoa está se relacionando com o que está à sua frente, não com o que ela vivenciou no passado.

No pesar preparatório, há pouca ou nenhuma necessidade de palavras. É mais um sentimento que se exprime mutuamente, traduzido, em geral, por um toque carinhoso de mão, um afago nos cabelos, ou apenas por um silencioso "sentar-se ao lado". ${ }^{16}$

No âmbito religioso, a atitude de oração pode ser expressão disso.

A partir da elaboração do quarto estágio, chega-se ao estágio da aceitação. Tal como o anterior, ele se caracteriza pelo privilégio do silêncio e da comunicação não verbal. Kübler-Ross adverte que não se deve confundir aceitação com felicidade nem com resignação. ${ }^{17}$ A resignação seria a desistência antecipada de lutar pela vida. Para o processo de cura, tal luta é fundamental. A aceitação, pelo contrário, é o final de um processo de reflexão profunda diante do reconhecimento do inevitável. Em todo caso, a aceitação, por parte de familiares e mesmo de equipes médicas, desta aceitação feita pela pessoa moribunda é bastante difícil. Familiares e profissionais muitas vezes a enxergam como desistência. A visão de que se trata de um ponto alto do processo é descrita por Kübler-Ross nesses termos:

(...) descobrimos que os pacientes que melhor reagem são aqueles que foram encorajados a extravasar suas raivas, a chorar durante o pesar preparatório, a comunicar seus temores e fantasias a quem puder sentar-se e ouvi-los em silêncio. Deveríamos tomar consciência do enorme trabalho em alcançar este estágio de aceitação, levando a uma separação gradativa (decatexia), onde não há mais diálogo. ${ }^{18}$

À esperança Kübler-Ross dedica todo um capítulo de seu escrito. Não se trata, para ela, de um estágio, mas de um fator que acompanha

\footnotetext{
${ }^{16}$ Ibid., p. 97.

${ }^{17}$ Ibid., p. 120-1.

${ }^{18}$ Ibid., p. 126.
} 
sempre todo o processo. Nem nos momentos de maior desilusão exterior a esperança deixa de ter seu espaço no âmago da pessoa. De certo podese perceber aqui a convicção da autora de que a esperança é um fator constituinte da existência humana, o que daria ocasião para a reflexões também quanto às implicações disso para a religiosidade. Em todo caso, Kübler-Ross mostra como a esperança se manifesta na pessoa doente tanto na crença em possibilidades sobrenaturais de cura quanto na confiança na atuação concreta dos profissionais de saúde. Para a autora, a destruição desta esperança não é correta, à medida que implica um julgamento quanto a possibilidades que fogem do controle humano.

Em todo caso, é útil ainda observar que o modelo de Kübler-Ross para o processo aqui exposto não deveria ser visto em termos de uma realidade estanque, enquanto uma fórmula para a existência, como se todo mundo precisasse passar por tais etapas para ter uma morte correta. Trata-se de um esquema para compreender as reações de pessoas moribundas e de pessoas relacionadas com elas. Neste sentido, deve-se pressupor a existência de sobreposição desses estágios, assim como um processo de idas e vindas de um estágio para o outro. $\mathrm{O}$ esquema de estágios representa as atitudes dominantes da pessoa em certos momentos.

\section{Interrelações possíveis}

O capítulo 13 do texto da História de José o Carpinteiro traz uma oração de preparação. Ali se expressa o temor que a morte causa. Há uma série de solicitações, as quais poderiam ser relacionadas com o estágio da barganha apresentado por Kübler-Ross. A confissão de fé final pode ser vista como o elemento oferecido pelo moribundo neste momento de barganha. Por outro lado, também poderia se ver aqui algo da expressão da negação da morte, tanto na confissão em si quanto na simbologia das peregrinações da alma após a morte. De certo que esta última comparação não seria muito correta se tomada num sentido literal, devido à distinção histórico-cultural que pressupõe cosmovisões muito distintas entre a época do texto e a atual. Talvez se possa pensar que essa distinção opere no sentido de que a negação da morte hoje se apresente com mais 
força do que no passado, sendo a perspectiva de progresso tecnológico e científico em grande parte responsável por isso.

A descrição da enfermidade terminal, assim como está nos capítulos 14 e 15 da narrativa, mostra a necessidade de um confronto existencial com a morte enquanto um elemento da vida humana. Neste sentido, ele representa a superação da negação pura e simples. Para o leitor moderno, talvez o realismo do texto provoque alguma repulsa por sua concreticidade. Isso justamente porque o texto atinge em cheio a negação generalizada da morte, uma vez que esta não se restringe a um estágio individual, mas perpassa a cultura moderna.

Os salmos de lamentação presentes no texto podem apontar para duas coisas. Por um lado, eles expressam o estágio de raiva diante da situação reconhecida como insuperável. Por outro lado, podem expressar também o estágio de reflexão caracterizado como depressão por Kübler -Ross. No caso do texto da narrativa, sua natureza particular faz com que sua composição expresse com alguma força os pressupostos religiosos que o motivaram. Deste modo, a expressão de raiva e de depressão é um tanto quanto mitigada, dando espaço para considerações morais. Especialmente quando se compara com o caráter dialogal dos textos do livro de Jó e de salmos de lamentação, nota-se um certo retrocesso na livre expressão dos sentimentos humanos. Cabe notar, no entanto, que mesmo assim a narrativa da História de José o Carpinteiro dá muito mais espaço para essa livre expressão do que a que se pode encontrar a respeito em nossa cultura moderna negadora da morte.

O capítulo 17, que expressa a ligação de José com Jesus, não encontra um paralelo nos estágios descritos por Kübler-Ross. Isso possivelmente em virtude do caráter confessional da narrativa neste ponto. Apontando para a relação histórica entre José e Jesus e para a confissão na salvação trazida por Este, o texto aparece como um consolo diante da situação. Cabe observar, no entanto, que não se trata simplesmente de um consolo barato. Pelo contrário, este é resultado da vivência profunda da situação. Em termos psicológicos, poderia se ver aqui um espelho da resposta encontrada pelo moribundo à sua situação, não uma pregação simplória a ser feita por outros a quem se encontra nela.

Com a introdução da reação de Maria, no capítulo 18, ocorre uma generalização que já havia sido preparada no capítulo anterior. A reflexão 
em torno da morte de José atinge o leitor, e o paralelo que se faz com a morte futura de Jesus representa esta preparação a que o leitor é convidado. O paralelo com o esquema interpretativo oferecido por Kübler-Ross deve se dar com as reflexões que esta faz acerca da analogia entre o processo que ocorre com o doente terminal e o que ocorre com as pessoas de sua relação. No caso do texto narrativo, essa descrição sobre os familiares acaba tendo um alcance ainda mais amplo, à medida que implica a identificação dos leitores com os presentes junto ao leito.

O paralelo da narrativa no texto do capítulo 19 com as reflexões de Kübler-Ross sobre a situação durante os estágios de depressão e aceitação é notável. O ponto em comum, no caso, é a prioridade da comunicação não-verbal. Na narrativa, a visão e o tato se estabelecem como as formas de vínculo privilegiadas neste momento. A importância da solitude e a situação de liminaridade da pessoa moribunda são realçados a partir destes elementos narrativos.

A descrição da agonia no capítulo 20 volta a dar atenção para a situação da família. Esta constante mudança de foco na narrativa entre o doente terminal e a família oferece a possibilidade de verificar a tensão entre a vivência do processo de morte pelo moribundo e a que experimentam os familiares. Inclusive as distinções dessa vivência por parte dos diferentes membros da família transparecem. Enquanto alguns aceitam, outros vivem ilusão momentânea.

Por fim, o capítulo 21 aparece como o auge do processo. Nele se conjugam de uma forma narrativa simbólica a situação real e a esperança. Talvez justamente só literariamente, por meio de desenhos poéticos, se consiga estabelecer uma tal conjunção. A confusão entre aceitação da morte com esperança, por um lado, e negação ilusória, por outro, dificilmente pode ser desfeita em termos meramente conceituais. A simbologia na narrativa, por outro lado, pode oferecer uma tentativa de conjugação entre realidade e esperança, sem ilusão.

A análise poderia continuar com os elementos narrativos posteriores à morte de José, examinando a reação de familiares e amigos a ela (cf. capítulos 23ss). No entanto, as indicações a essa reação já presentes na parte da narrativa considerada mais essencial permitem ter uma noção suficiente da inter-relação possível entre a narrativa religiosa e o modelo interpretativo oferecido por Kübler-Ross. 


\section{Conclusão}

Duas coisas seria incorreto concluir da presente análise. A primeira má impressão teria quem quisesse ver aqui uma tentativa de "canonização" do escrito analisado. A perspectiva adotada não é de modo algum dogmática. Mesmo assim, a análise feita mostra que também textos nãocanônicos podem apresentar coisas frutíferas para a reflexão. Assim, no máximo se poderia ver aqui, com relação a este apócrifo neo-testamentário, aquilo que Lutero escreveu na sua introdução aos apócrifos véterotestamentários por ele inseridos como apêndice à sua tradução da Bíblia: Que tais escritos não fazem parte da Escritura canônica, mas que mesmo assim são bons para se ler. À parte disso, é evidente que a cosmovisão pressuposta na História de José o Carpinteiro não é mais atual. A tradição cristã também nunca definiu qualquer cosmovisão como cristã. Vale, portanto, para a leitura deste texto, a necessidade de se aplicar o princípio desmitologizador proposto por Bultmann ${ }^{19}$, reconhecendo que reinterpretados para dentro de uma visão atual tais textos apresentam contribuições importantes para a compreensão da existência humana.

A segunda má impressão seria a de que a proposta de Kübler-Ross seria um modelo pronto para julgarmos a adequação de indivíduos particulares ou de textos quanto ao processo de morte. Na verdade, seu modelo é utilizado aqui porque sua preocupação psiquiátrica tem feito surgir todo um desenvolvimento posterior de estudos, na interface entre a medicina e a psicologia, que é de grande alcance. Não havendo como dominar toda a literatura sobre a questão, a presente análise se restringiu a um diálogo com um modelo que representa este tipo de estudos. Outros estudos poderiam aprofundar bem mais o tipo de análise que aqui se faz, e se este tiver servido de inspiração para tal já terá cumprido sua missão.

O que, pois se pode concluir positivamente da presente análise?

1. A importância da crítica ao recalque puro e simples da realidade da morte. Diante da cultura otimista, confiante no progresso médico-tecnológico, é importante lembrar que de fato a morte é uma realidade. Sem menosprezar os avanços científicos, que

${ }^{19}$ Cf. BULTMANN, Rudolf. Desmitologização. In: . Crer e compreender, p. 11-45. 
certamente tem cumprido um papel importante na preservação da vida, é importante não se utilizar da ciência para fundamentar uma ilusão - a de que a morte é algo superado. Viver a morte como parte da vida é algo que tanto a antiga narrativa aqui analisada quanto os estudos de Kübler-Ross nos ensinam.

2. A importância da expressão simbólica dos fenômenos ligados ao processo de morte. A perspectiva otimista ilusória acima descrita também tem provocado um esvaziamento da importância dada aos elementos simbólicos. É preciso resgatar esses elementos, que se encontram na literatura religiosa, muitas vezes rechaçada como fonte de conhecimentos importantes. Por outro lado, a análise aqui esboçada convida a outras pesquisas, sobre a simbologia na arte, por exemplo. Toda uma pesquisa sobre a presença das representações da morte na arte (pense-se no Realismo, no Surrealismo e no Expressionismo, para permanecer no período moderno) poderia suscitar a redescoberta desse elemento existencial ausente das representações cotidianas e da cultura de massas, alcançáveis pelo senso comum. O recalque da realidade da morte precisa ser combatido para a boa saúde espiritual do mundo moderno.

3. A existência de representações simbólicas destes fenômenos nas diversas tradições religiosas e no cristianismo em particular. Muitas vezes se veem resumos um tanto apressados do fenômeno religioso como se sua função fosse simplesmente oferecer uma resposta ao enigma da morte, principalmente no que diz respeito aos mistérios inacessíveis do que se segue a ela. Numa direção um pouco distinta, o que aqui se propõe é que investiguemos as próprias representações religiosas da morte. Certamente a moldura dessas representações mostra as convicções profundas que a confissão religiosa defende. Por outro lado, o modo como se relacionam essas convicções com a realidade concreta é um objeto de análise muito interessante. No caso da presente análise, podese constatar uma inter-relação muito promissora entre confiança cristã e reconhecimento da realidade de modo não ilusório.

4. A contribuição à existência humana do auxílio fraterno com vistas à dignidade no momento de se despedir dessa existência. 
Num sentido prático, a contribuição que as tradições religiosas, e particularmente a cristã, tem a oferecer para o acompanhamento das pessoas moribundas é notória. A experiência acumulada na vivência da solidariedade com doentes, especialmente terminais, não deve ser negligenciada. Por outro lado, considerando-se a religiosidade um componente intrínseco à vida humana, receber tal acompanhamento de forma digna é inclusive um direito de cada pessoa. Evidentemente, com a ênfase na dignidade se quer também rechaçar toda e qualquer forma de abordagem humilhante aos doentes terminais. Infelizmente, muitas vezes a religião é usada não para auxiliar as pessoas no acompanhamento desse momento da vida, mas para atormentá-las com pregações moralistas ou conversionistas de última hora. A crítica a tais abordagens é uma intenção implícita da presente análise.

Por fim, não se pode concluir sem afirmar o profundo sentimento de esperança que perpassa tanto a narrativa da História de José o Carpinteiro quanto a proposta de Elisabeth Kübler-Ross. Nenhum dos dois textos é um parâmetro para a correção doutrinária do cristianismo. A narrativa analisada apresenta muitas crenças historicamente condicionadas. Kübler-Ross, em textos posteriores, enveredou por especulações cujo caráter científico não cabe aqui nem descrever nem criticar. Em todo caso, o estudo dela aqui utilizado representa um modelo interpretativo capaz de instrumentalização. Neste sentido, a esperança realista aparece como um modelo de auxílio tanto para a reflexão quanto para a prática de acompanhamento de doentes. Essa tensão produtiva entre esperança e realidade deveria acompanhar tanto o desenvolvimento teológico das convicções religiosas quanto o processo de avanço tecnológico.

\section{Referências Bibliográficas}

BULTMANN, Rudolf. Crer e Compreender. São Leopoldo: Editora Sinodal, 1987.

KOVÁCS, Maria Júlia. A morte e o desenvolvimento humano. $2^{\mathrm{a}}$ ed. São Paulo: Casa do Psicólogo, 1992. 
KÜBLER-ROSS, Elisabeth. Sobre a Morte e o Morrer. $4^{\text {a }}$ ed. São Paulo: Martins Fontes, 1991.

SANTOS OTERO, Aurélio de (ed.). Los Evangelios Apócrifos. 6 a ed. Madrid: La Editorial Catolica, 1988. (Biblioteca de Autores Cristianos). 